\title{
Participação política e subjetividade - Narrativas de vida de trabalhadoras rurais do sul do Brasil
}

\author{
Rita de Cássia Maciazeki-Gomes \\ Conceição Nogueira \\ Universidade do Porto, Portugal \\ Claudia Lazcano Vázquez \\ Maria Juracy Toneli \\ Universidade Federal de Santa Catarina, Brasil
}

\begin{abstract}
Resumo
Este estudo aborda a intersecção entre participação política e subjetividade a partir análise das narrativas de vida de mulheres trabalhadoras rurais. Trata-se de um estudo qualitativo, de cunho exploratório, que envolveu sete mulheres que ocupam posições de liderança no movimento social do campo, na região sul do Brasil. Para produção dos dados utilizou-se de instrumentos variados como observação, registro em diário de campo, conversas informais e entrevista. As análises temáticas identificaram a participação política como dispositivo de subjetivação ao produzir elos entre público e o privado, ao pautar o privado como político, ao estruturar um discurso coletivo e ao abrir espaços para reinvenção dos modos de vida.
\end{abstract}

Palavras-chave: Mulheres; Contextos rurais; Política; Processos de subjetivação.

\section{Politic participation and subjectivity - Narratives of life of rural worker women from southern Brazil}

\begin{abstract}
This study addresses the intersection between political participation and subjectivity from the analysis of the narratives of life of rural worker women. This is a qualitative study of nature exploratory, involving seven women in leadership positions in the social movement of the field, in southern Brazil. For production data was used for various instruments such as observation, field diary, informal conversations and interviews. The thematic analysis identified the political participation as a subjectivation device by producing links between public and private, at considering private as political, to structure a collective discourse and to open spaces to reinvention of ways of living.
\end{abstract}

Keywords: Women; Rural contexts; Politics; Subjectivation processes.

\section{Participación política y subjetividad - Narraciones de vida de trabajadoras rurales del sur de Brazil}

\section{Resumen}

El estudio aborda la relación entre participación política y subjetividad a partir del análisis de narraciones de vida de mujeres trabajadoras rurales. Se trata de un estudio cualitativo, exploratorio, que envuelve siete mujeres que ocupan posiciones de liderazgo en el movimiento social del campo en la región sur de Brasil. Para la producción de los datos se han utilizado instrumentos como observación, registro de diario de campo, conversaciones informales y entrevistas. Los análisis temáticos han identificado la participación política como dispositivo de subjetivación al producir nexos entre lo público y lo privado, pautar lo privado como político, estructurar un discurso colectivo y abrir espacios para la reinvención de los modos de vida.

Palabras clave: Mujeres; Contexto rural; Política; Procesos de subjetivación. 
Este estudo aborda a intersecção entre participação política e subjetividade a partir análise das narrativas de vida de mulheres que ocupam posições de liderança no movimento de trabalhadoras rurais, no sul do Brasil. Para isso, nos aliamos a Michel Foucault (1979/1995) ao compreender a subjetivação como processo de constituição da subjetividade, produzida e condicionada aos jogos de forças constituídos por relações de poder. Entendemos subjetividade, também apoiadas na discussão efetuada por Fernández (2008), como produção que evoca às ações e às práticas produzidas no entre/com os outros, em meio às inscrições históricas, culturais, econômicas, psíquicas e sexuais. A produção de subjetividade, assim, está associada à produção política, ou seja, às relações entre as pessoas em determinado contexto atravessadas por relações de poder.

Interessa-nos estudar os modos de produzir-se mulher, trabalhadora rural, associados à multiplicidade de forças que transversalizam as relações cotidianas, bem como, aos agenciamentos singulares associados aos modos de vida de cada uma dessas mulheres. Daí a necessidade de tomar gênero como processo, perpassado pelas experimentações do viver, numa perspectiva interseccional (Nogueira, 2013). As análises interseccionais, ao levarem em conta as relações familiares, sociais, culturais, econômicas, políticas, com o corpo, saúde e sexualidade e étnicoraciais constituídas por relações de poder (Nogueira, 2011) ampliam e complexificam as discussões de gênero. Assim, já não é possível pensar gênero a partir de um único formato, mas justamente como algo que se constitui nesses movimentos constantes de um vir a ser mulher (Oliveira, 2012).

De modo mais específico, as reflexões sobre as produções de gênero, neste estudo, estão interseccionadas pelo recorte da participação política. Tomada em análise, a participação política no movimento de mulheres trabalhadoras rurais opera como agenciador entre o privado e o público. O movimento ao defender pautas que produzem o borramento com as fronteiras do que é da casa, do que é do trabalho, e assim do que pode ser problematizado coletivamente, contribui para a desnaturalização de temáticas cristalizadas, e ao mesmo tempo, facilita as reflexões sobre os modos de vida, em suas relações pessoais e, também, comunitárias. Por isso, para a aproximação, estudo e análise dessas questões defendemos uma perspectiva interseccional de gênero, como uma estratégia potente e sensível, ao se propor a escuta das narrativas das experiências em suas múltiplas realidades vividas (Nogueira, 2013).
As discussões pautadas pela interseccionalidade auxiliam a pensar os processos de subjetivação agenciados através das narrativas dos modos de ser mulher, trabalhadora rural, participante de movimento social do campo, moradora da região sul do Brasil, casada, mãe, filha, cristã. Mais do que uma caracterização descritiva sobre essas mulheres, interessa-nos a problematização de como são produzidas essas narrativas que constituem modos de ser mulher atravessados pela participação política.

Cabe salientar que a temática da participação política ainda é pouco estudada no campo da Psicologia Social (Costa, Machado, \& Prado, 2008). Bem como as questões de gênero e ruralidade também não receberam atenção e força nos estudos de gênero e na Psicologia Feminista que, de modo geral, têm se voltado de modo prioritário para as questões e problemáticas dos espaços urbanos (Maciazeki-Gomes, Nogueira, \& Toneli, 2016). Ao demarcar essas lacunas na literatura, este estudo visa contribuir com as discussões sobre gênero em contextos rurais, com enfoque nos elementos subjetivos da participação política.

\section{Movimento de mulheres trabalhadoras rurais e participação política}

As relações entre participação política e subjetivação mostram-se complexas, uma vez que sua produção constitui-se de diferentes formas por se mover em muitas direções e sentidos. De modo que, se por um lado, os lugares de invisibilidade e submissão destinados às mulheres em diversas partes do mundo produziram movimentos coletivos na luta pela garantia de seus direitos, de outro, a participação política inicialmente deslocada, acionou a problematização de posições subjetivas até então estabelecidas do que era e/ou deveria ser o papel da mulher na sociedade. O desafio está no mapeamento dessas relações de forças em sua multiplicidade, produzidas no/pelo/em movimento de mulheres rurais.

A organização do movimento de mulheres rurais pode ser associada a um conjunto de novos movimentos sociais que emergiram no Brasil, no contexto da redemocratização, pós-ditadura militar (Schaaf, 2003). As vozes das mulheres começaram a ecoar e produzir efeitos no final década de 1970 e ganharam mais força nos próximos anos. A década de 1980, marcada pela efervescência e o desenvolvimento de inúmeros movimentos sociais, contribuiu para a mobilização das trabalhadoras rurais na luta pelos seus direitos, por todo país.

Ao encontrar espaços de acolhida junto aos movimentos populares e ao movimento sindical 
rural, em diferentes partes do país resguardadas suas devidas especificidades, as reivindicações das mulheres ganharam impulso e se fizeram ouvir na sociedade (Daron, 2003; Mourão, 2011; Paulilo \& Silva, 2007; Prado, Campici, \& Pimenta, 2004; Schaaf, 2003; Sales, 2007; Salvaro, Lago, \& Wolff, 2013; Salvaro, Lago, \& Wolff, 2014).

No final da década de 1980, a agenda de reivindicações do movimento estava voltada ao reconhecimento da mulher agricultora como trabalhadora rural e, assim, conquistar a garantia dos direitos sociais e previdenciários (Cardona \& Cordeiro, 2010) que as mulheres urbanas já possuíam. Ao mesmo tempo, exigia o rompimento com um ciclo histórico de desigualdades e opressões associado ao trabalho com a terra, às atividades domésticas não remuneradas e à pouca participação da mulher na gestão econômica da família. Situações essas, muitas vezes, associadas à baixa autoestima, situações de dependência, opressão e discriminação (Paulilo \& Silva, 2007).

Entre os resultados mais expressivos dessa luta está a inclusão na Constituição Federal (CF) de 1988 de direitos como: a) inserção para as trabalhadoras rurais do direito ao título da terra independente do estado civil, b) a extensão dos direitos trabalhistas dos segmentos urbanos para as trabalhadoras do campo e, c) o direito à Previdência (Cardona \& Cordeiro, 2010) ${ }^{1}$, entre outros.

Essas conquistas exigiram organização e mobilização de grupos de mulheres trabalhadoras rurais em assembleias e encontros em níveis local, regional e nacional por todo país (Cordeiro \& Cardona, 2010; Prado, Campici, \& Pimenta, 2004; Sales, 2007). Por sua vez, a consolidação das conquistas e ampliação dos direitos demandaram a continuidade e o fortalecimento do movimento de mulheres rurais.

Sem dúvidas, todo esse contexto social e cultural em efervescência propiciou a abertura de níveis maiores de participação política das mulheres e contribuiu para importantes mudanças subjetivas nos modos de ser mulher trabalhadora rural, sindicalizada, no sul do Brasil. É sobre esses processos que aqui nos dedicamos. Neste estudo, ao situarmos a história do movimento de mulheres trabalhadoras rurais, direcionamos nosso enfoque para as mulheres associadas à Federação dos Trabalhadores da Agricultura (FETAG) da região sul do Brasil. A discussão central está em problematizar a participação política e seus efeitos no processo de subjetivação dessas mulheres trabalhadoras rurais.

\footnotetext{
${ }_{1}$ Para um aprofundamento das conquistas do movimento de mulheres, a partir do final da década de 1980, ver Daron (2003) e Mourão (2011).
}

\section{A política como dispositivo de subjetivação}

Pensar a participação política como dispositivo de subjetivação (Foucault, 1979/1995) remete a problematizar a rede de relações imbricadas ao processo histórico de constituição do movimento de mulheres, suas pautas e bandeiras de lutas; a singularidade das histórias de vida de cada uma das mulheres participantes do movimento; os atravessamentos de pautas coletivas, a formação da identidade militante e, assim, os jogos de forças imersos nas relações estabelecidas dentro e fora do movimento de mulheres.

Para Foucault (1979/1995) o dispositivo constituise a partir de um conjunto heterogêneo que engloba entre outras coisas discursos, instituições, leis, proposições filosóficas definindo-se como a rede que se estabelece entre esses elementos. A história do movimento de mulheres trabalhadoras rurais associada à singularidade das histórias de vida de cada uma das mulheres, em sua diversidade de composições constitui-se o mote para pensar a participação política como dispositivo. O borramento dos espaços público-privado contribui para acionar o político que irrompe apesar das barreiras anteriormente preestabelecidas. Dentre esse contexto, propomos a leitura da participação política no movimento social de mulheres como dispositivo de subjetivação, à medida que agencia e produz modos de vida.

Ao tomarmos o movimento de mulheres como parte dos movimentos sociais da década de 1980, observamos semelhanças nas diferentes regiões brasileiras. Na sua composição esteve associado a uma matriz religiosa (Prado, Campici, \& Pimenta, 2004), à Comissão Pastoral da Terra (CPT) e às Comunidades Eclesiais de Base (Salvaro, Lago, \& Wolf, 2013), ao Movimento Sindical Rural, às agências de cooperação internacional e aos movimentos feministas (Cardona \& Cordeiro, 2010; Schaaf, 2003). Essas lentes imprimiram influências ideológicas ao movimento de mulheres.

Para além das diferenças regionais, o surgimento do Movimento das Trabalhadoras Rurais está atrelado às lutas das mulheres pelos direitos sociais e previdenciários, bem como às bandeiras em prol de visibilidade do trabalho da mulher e sua atuação também na esfera pública. A identidade política como organizador coletivo direcionou o repensar das próprias mulheres sobre si mesmas, suas condições de vida e seu lugar no mundo.

Para Costa, Machado e Prado (2008), a atuação política remete aos espaços construídos nas relações de cotidianidade, sendo que a constituição da identidade política se relaciona a três aspectos psicossociais: a 
formação de identidade coletiva, a transformação das relações de subordinação em relações de opressão e a demarcação de fronteiras políticas entre os grupos sociais. De modo que,

a identidade política configura-se, assim, como aquele elemento que, ao mesmo tempo, é possibilitado e constituído no interior do processo mobilizatório e revela-se como elemento mediador da consistência interventiva dos grupos envolvidos na luta e, nessa medida, promove transformações subjetivas e objetivas tanto em indivíduos particulares como nas diversas esferas (espaço, lógica e prática) da vida cotidiana; realiza, pois, a potência emancipatória das formas de ação coletiva em diferentes espaços da cotidianidade (Prado, Campici, \& Pimenta, 2004, p. 314).

Cabe ainda, um olhar mais atento para a ideia de identidade política. Ao agrupar "as mulheres" em prol de lutas coletivas corre-se o risco de cair em discussões essencialistas de que todas as mulheres seriam iguais e teriam suas demandas acolhidas no interior do movimento. Demarcando esse incômodo, entendemos a identidade política como um agregador na acolhida à diferença e à diversidade. Neste sentido, nos aliamos a Prado e Toneli (2013) no reconhecimento da existência nas lutas políticas contemporâneas de "conflitos e antagonismos marcados por sujeitos constituídos por um conjunto de posições de sujeitos. A identidade de tal sujeito múltiplo e contraditório é construída discursivamente por vários componentes como sexo, raça, etnia, classe, idade e sexualidade, entre outros" (p. 355). A identidade, neste enfoque, ativada pela inserção e participação política é vista como plural, distanciando-se de uma matriz essencialista, evoca os diferentes sentidos relacionados aos modos de constituir-se mulher trabalhadora rural. Aqui, a noção de identidade tomada desde um campo de experiência (Prado Filho, 2014), se desloca de demarcações identitárias definidas à priori para salientar identidades "históricas, fluidas e não fixas" (Guareschi et al., 2002).

O estudo do marcador "identidade", no movimento de mulheres trabalhadoras rurais participantes de movimento social, implica o mapeamento de linhas móveis, e por vezes em constante tensão, que dizem de "um comum" associado as "mulheres, trabalhadoras, rurais, e..." como parte de um grupo. A adição "e" a esse grupo contempla a existência de linhas de fuga que instauram posicionamentos singulares pautados pelas histórias de vida, atravessados por contextos sócio, histórico, político, econômico e culturais diferenciados. A identidade política, neste caso, é vista de um lado como uma ferramenta que permite a unidade do grupo, como movimento de reivindicação de direitos, e de outro, uma ferramenta produtora de estilhaçamento, estranhamento e resistência frente aos jogos de forças que imprimem a estagnação em matrizes identitárias fixas a partir da homogenização e a normatização dos corpos. Nesta perspectiva "identidade" passa a ser compreendida via (des)identificação.

A participação política no movimento social contribuiu para que as mulheres pudessem repensar a tradicional divisão de papéis/atribuições, entre homens e mulheres, associados à família e ao trabalho, ao demarcarem coletivamente suas bandeiras de luta. A superação da invisibilidade das mulheres rurais e seu reconhecimento como sujeito político ganhou espaços em organizações sociais mistas, como sindicatos, associações e cooperativas. A inserção das mulheres em movimentos sociais do campo possibilitou a abertura de discussões sobre os modos de vida naturalizados no cotidiano, bem como o repensar posições discursivas associadas a opressão e violência dentro do contexto familiar e comunitário (Paulilo \& Silva, 2007; Prado, Campici, \& Pimenta, 2004).

Ao encontrarem acolhida e espelhamento para suas questões, o privado torna-se político, na medida em que "o conceito de privacidade compartilhada propicia a politização de experiências percebidas, a partir das dicotomias público-privado e pessoalpolítico, como pré-políticas ou, muitas vezes, como anti-políticas" (Costa, Machado, \& Prado, 2008, p. 326). Neste sentido, as questões de foro íntimo passam a ser discutidas a partir da lógica da experiência e seus efeitos na vida das mulheres. As experiências compartilhadas deslocam-se do nível individual para um plano coletivo. Numa perspectiva foucaultiana, a noção de experiência é pensada e problematizada na interseção entre tempo, espaço, condições socioeconômicas, políticas e culturais, constitui "inquietação que se torna ponto de partida para um trabalho teórico, ético e político" (Rodrigues, 2014, p. 23). Assim, as experiências narradas não dizem de uma suposta interioridade, mas demarcam produções coletivas (Scott, 1998) de modos de constituir-se mulher, trabalhadora rural do sul do Brasil. Mais do que dar visibilidade às experiências em si, interessanos pensar sua produção e operacionalização em meio à vida, como possibilidade de (re)criação de si e do/ no mundo. A escuta e o compartilhar das histórias de cada uma, reverbera no coletivo, diz de um nós que se fortalece para os embates cotidianos. Assim, a participação no movimento social contribuiu para o 
(re)pensar sobre os modos de ser mulher, trabalhadora rural, mãe, esposa.

A composição da diversidade de vozes produziu um modo de ser coletivo em que a diversidade abria espaço para diferença no movimento de mulheres rurais. Por um lado, as religiosas inspiradas na Teologia de Libertação davam "consolo e esperança àquelas que, na vida cotidiana, enfrentavam grande desigualdade e fornecia-lhes argumentos da Bíblia para que se levantassem contra a opressão e alcançassem a libertação" (Schaaf, 2003, p. 415). Por outro, as religiosas incentivam a participação das mulheres rurais nos movimentos sindicalistas e, as feministas reivindicavam mais participação nas articulações e decisões políticas dentro dos espaços de disputas de poder (Paulilo \& Silva, 2007).

O modelo do sindicalismo rural masculino também contribuiu para que as mulheres se mobilizassem para serem reconhecidas pelos homens, a partir de uma linguagem do mundo dos homens. Neste sentido, configurou-se uma vinculação a uma estrutura sindical conservadora, atrelando a mulher rural à posição de trabalhadora e não à de pequena proprietária rural (Tedeschi, 2007). As discussões sobre as relações entre classe e gênero, ou a falta delas, fizeram com que se mantivesse a permanência do discurso da classe como o eixo consensual de mobilização reverberando as desigualdades entre homens e mulheres no que concerne às relações de poder e gênero. Essas reflexões apontam para problematização do espaço/lugar das discussões de gênero dentro do movimento e sinalizam a necessidade de uma maior visibilidade no enfrentamento destas questões.

Pensar a participação política como dispositivo de subjetivação abre espaço para composição de uma identidade coletiva que ancora e defende as necessidades das mulheres a partir de uma privacidade compartilhada (Costa, Machado, \& Prado, 2008), ao mesmo tempo, demarca modos de ser mulher trabalhadora rural articulada às narrativas deste mesmo coletivo. A seguir apresentaremos as reflexões do estudo realizado com o movimento de trabalhadoras rurais do sul do Brasil, e buscaremos operar a dinâmica complexa entre essas linhas de forças que compõem os modos de ser mulher atrelados à participação política e subjetivação.

\section{Método}

Trata-se de um estudo qualitativo, de cunho exploratório, e faz parte de um estudo maior no qual foram entrevistadas vinte e duas trabalhadoras rurais participantes de movimento social do campo. A pesquisa foi realizada em uma cidade da região sul do Brasil, com características da colonização alemã e com uma população de 14.890 habitantes, 7.283 residentes na área urbana e 7607 na área rural, conforme dados do município. Em relação às participantes, todas possuíam ligação com o Sindicato dos Trabalhadores Rurais (STR) do município e estavam inseridas em atividades da FETAG. Para este estudo, foram selecionadas sete que apresentavam em comum trajetórias como fundadoras ou lideranças do movimento.

No que se refere à caracterização sócio-demográfica, as sete trabalhadoras rurais entrevistadas possuíam idades entre 32 e 69 anos. Seis declararamse casadas e uma solteira. Quanto à escolaridade, uma delas declarou que não estudou, uma tinha o ensino fundamental incompleto, uma ensino médio incompleto e quatro, ensino médio completo. Todas declararam-se agricultoras.

A pesquisa atendeu à adequação dos aspectos éticos conforme as resoluções no $196 / 96$ versão 2012 , e no 251 de cinco de agosto de 1997 do Ministério da Saúde, assim como contemplou uma postura ética e política, atendendo as resoluções do Conselho Federal de Psicologia. As entrevistas foram realizadas em dia e local, previamente agendados e escolhidos pelas participantes, sendo que a maioria das entrevistadas preferiu seu local de residência. Neste sentido, foi possível uma aproximação dos espaços da casa, da família e do trabalho.

Para produção dos dados utilizou-se de instrumentos variados como observação, registro em diário de campo, conversas informais e entrevista. A composição da entrevista contou com uma caracterização sócio-demográfica e com questões norteadoras sobre como era o modo de vida na infância - as relações familiares e a escolaridade; as relações de trabalho e os aspectos relacionados à saúde e violência. A entrevista teve como foco gerador a participação política e foram conduzidas de modo a dar espaço para que outros temas e narrativas, além das citadas, pudessem emergir.

O material produzido foi trabalhado a partir da Análise Temática (Braun \& Clarke, 2006; Clarke \& Braun, 2013). A partir desta proposta de análise procurou-se identificar os temas agregadores e representativos das narrativas dos modos de vidas das mulheres. $\mathrm{O}$ conceito organizador central que articulou as discussões dos dados foi a participação política. Mais do que um agrupamento daquilo que se repetiu nos dados, buscou-se a representatividade da pluralidade das narrativas em sua singularidade, de modo a estabelecer conexões entre as histórias de vida das entrevistadas e o movimento de mulheres trabalhadoras rurais. 


\section{Resultados}

A partir da análise dos dados foram identificados dois eixos centrais, organizados pelas seguintes categorias temáticas:

1. Participação politica: o privado é político. Neste eixo identificamos duas categorias temáticas: a) inserção e espaços de atuação; b) avanços e desafios na atuação política.

2. Participação política como dispositivo de subjetivação. Neste eixo identificamos duas categorias temáticas: a) Efeitos da participação política nos modos de vida das trabalhadoras rurais; b) participação política como possibilidade de (re)invenção de si.

\section{Participação política: o privado é político}

Entre as sete mulheres entrevistadas, a inserção no movimento de mulheres esteve associada ao reconhecimento da presença de situações de opressão e invisibilidade no cotidiano, bem como à necessidade de produzir ações para mudança desta realidade. A participação política é interpretada, por algumas, como "um chamado":

me envolvi na comunidade desde muito cedo, e ai foi indo [...] em 83 teve a mobilização do leite aqui... uma mobilização que tranco as indústria do leite, enfim, e ai eu me senti assim, assim, chamada pra pega o microfone e fala... Que a questão do leite na época era, principalmente pela questão das mulheres, quem coordenava, e eu como mulher, pensei, não, uma jovem mulher, peguei o microfone e ai chamo a atenção né [...] assessor do sindicato, conhecia já mais uma outra jovem que conhecia, uma moça, é, começamo a fala em funda um movimento de mulheres, mulher tem que se organiza. (TR1, 56 anos)

A partir das falas das mulheres, é possível associar o início do movimento atrelado a necessidades concretas do cotidiano, como a "mobilização do leite". A articulação e organização das pautas de luta incluía reivindicações associadas à valorização da agricultura e do acesso à terra. As discussões, assim, para além de um recorte restrito de gênero articulavam questões de classe (Salvaro, Lago, \& Wolf, 2013). Sendo que, "as questões de gênero e classe se apresentam como importantes mobilizadores de militância política, constituição de sujeitos e subjetividades" (Salvaro, Lago, \& Wolf, 2014, p. 52).

Pelas pautas abordarem a melhoria das condições econômicas e os interesses de toda família, nos bastidores da organização do movimento o apoio e a participação da família também foi ponto decisivo.

Eu caminhei junto, eu não tinha medo, coloquei uma bolsinha aqui também junto pra não perder, o neném em cima do braço com 12 quilos... 14 quilos [...] E eu fui junto por que né, os outros com o pai com os filhos estavam em casa daí, nós fomos lá, com ônibus, eu pensei como é bom, tinha vez de ir lá e fizemos o esforço para que os agricultores vão ser mais valorizados. Porque naquela época os filhos... os agricultor não eram muito valorizados, para ganhar um dia a sua propriedade o seu pedaço de terra. (TR2, 69 anos)

Em alguns casos, mesmo tendo apoio e suporte da família, as mulheres não eram bem vistas na comunidade onde residiam. Ao deixarem suas casas e saírem em marchas pelo estado e pelo país enfrentavam a reprovação de outras mulheres que não faziam parte do movimento. $\mathrm{O}$ enfrentamento dos padrões morais $\mathrm{e}$ religiosos impregnados na comunidade só foi possível a partir da participação com o incentivo do movimento "a romper com a rígida divisão de papéis, com o lugar já predeterminado na família, no trabalho, e a ocupar espaço no campo político" (Sales, 2007, p. 442).

E ai assim, quando eu saia ele cuidava minha filha... de 85, 86 eu já fui pra Brasília... com 3 anos, eu já deixei a guria, a criança em casa, eu sei que fui muito criticada, assim pelos vizinhos, pela comunidade, como é que a mulher deixa a criança pro marido. Claro, minha mãe veio ajuda lá em casa, então já começa por ai mostra a diferença [...] Pra época foi um escândalo, assim, e ai foi este comentário "como é que o marido vai cuida a criança, tá viajando, tá saindo... (TR1, 56 anos)

O processo de mobilização e militância culminou com as conquistas dos direitos sociais e previdenciários impressos na C.F. de 1988. A participação política no movimento fortaleceu a inserção das mulheres em outros espaços de atuação como em cooperativas, sindicatos, gestão da saúde, políticas públicas, grupos comunitários e religiosos.

Hoje eu sou diretora do conselho fiscal do sindicato e coordenadora do movimento de mulheres do municipio do sindicato neh? porque nos temos o movimento de mulheres que é de mulheres rurais... hoje são vinte e oito anos de organização desse grupo de mulheres que hoje eu tô na coordenação 
[...] dai hoje também faço parte da diretoria da rede que é uma ONG de S.R [...] Então eu hoje, represento o Sindicato de S.C. na rede que é uma ONG que eu tô representando lá e hoje eu sô secretaria desta entidade de lá da rede [...] que é também que é uma unidade, que são da questão do cooperativismo..., dai então tô participando da diretoria... e sô secretaria [...] E hoje também sou presidente da casa familiar rural de S.C. - Filhos da Terra, que é a atividade que os jovens estudam por alternância e que eles fazem um curso técnico formado em agricultura familiar. Então hoje também sou presidente da casa, e também hoje sou vice coordenadora do movimento regional de mulheres trabalhadoras rurais da região. Então provavelmente ano que vem vou ser coordenadora regional das mulheres da regional bastante movimentos! (TR4, 46 anos)

Após quase trinta anos dessas conquistas e a consolidação do movimento de mulheres como um espaço de reivindicação de seus direitos, os desafios a serem enfrentados estão associados à adesão e ao fortalecimento da mobilização com a participação da nova geração. Corroborando com os estudos de Salvaro, Lago e Wolf (2014), constata-se um envelhecimento das mulheres militantes, sendo que, das sete entrevistadas, cinco possuíam idades iguais ou superior a 44 anos. Entre as preocupações está como impulsionar a renovação do movimento.

Como é dificil hoje trazer uma mulher para o debate. Não tem tempo! Com todas as tarefas que a mulher tem hoje elas se envolvem na comunidade, na produção de alimentos, mas de uma certa forma tem mais serviço em casa. Então pra elas vir para um debate pra discutir qual é o nosso papel da mulher é mais complicado. Ocupar os espaços. É dificil hoje tu completar uma diretoria de um sindicato. Hoje foi aprovado 50\%, então a paridade, mas como é que nós vamos fazer? [...] esse ano que para as próximas diretorias tem que ter $50 \%$ de mulher na diretoria... É um desafio... um desafio que a mulher possa sair de casa e se libertar. Ela fica de certa forma um pouco mais cômoda em casa, Naquela época como dizia Vanise ela só ia porque precisava de uma aposentadoria precisava lutar por isso. (TR1, 56 anos)

Os espaços conquistados agora exigem a presença das mulheres em diversas instâncias de participação. A ocupação desses espaços muitas vezes é dificultada por uma série de atividades ligadas ao trabalho na propriedade que são impostos no cotidiano às mulheres (Sales, 2007). Se os espaços formais ligados a representação e atuação política de determinadas organizações mostram-se como um problema a ser enfrentado, por outro lado constata-se que atuação política das mulheres ganha outros setores da sociedade.

A inserção das mulheres em diferentes frentes de participação política operou mudanças no modo ver, compreender e atuar no mundo. A rede complexa de relações atravessadas pelos efeitos da participação política será abordada no próximo tema.

\section{Participação política como dispositivo de subjetivação}

Nas falas das trabalhadoras rurais a participação política insere-se como possibilidade de mudança no modo de se inscrever no mundo. O desassossego com as questões subjetivas associadas aos espaços privados, ao ser compartilhado no coletivo, ganha força e contribui para que outras mulheres ao socializarem seus incômodos, possam ajudar-se mutuamente a romper com os ciclos familiares e sociais que se repetem de geração a geração. A participação política, deste modo auxilia no rompimento com posições tradicionais de gênero. Diferente dos estudos de Pinto, Pontes e Silva (2013), as mulheres entrevistadas não acreditam que a função da mulher esteja associada aos cuidados da casa.

Comecei assim a entrar em discussão do município e politica aquela coisa toda [...] Filha naquela tarde com doze anos que tu me disse que ia se casa pra ser livre eu nunca acreditei. Eu disse: pai eu te falei que eu ia ser livre e hoje eu sou. Porque eu disse pra ele: que homem nenhum tem direito de mandar em mulher nenhuma. Sabe, então ele disse que jamais acreditaria isso que eu tinha falado pra ele que ia fazê, ia sê. Eu falei: eu sou! (TR4, 46 anos)

A participação política se dá, também, como parte de um processo crítico, atravessado por processos socializadores imersos na vida cotidiana. De modo que, o acompanhar das novas gerações o envolvimento da mãe nas atividades do movimento de mulheres produziu incentivos à participação, ao trilhar um caminho que foi construído em meio as privações e as dificuldades enfrentadas.

Daí era assim, era de manhã cedo, de meio dia uns almoçavam e deixavam a comida esquentada porque era assim uns desembarcavam e uns embarcavam pra de tarde. Isso foi anos e anos 
sempre assim. Então quem tava ai segurando as pontas era a mãe e essa talvez era uma dificuldade eu sei que o sonho dela muitas vezes foi de viajar a Brasília né ela não conseguiu, mas hoje eu tô indo! (TR7, 33 anos)

A participação política marca e produz efeitos nas vidas das mulheres em diferentes fases da vida, inclusive na velhice. Rompe com os limites do movimento de mulheres e adentra diferentes espaços da comunidade. A posição de sujeito político (Prado \& Toneli, 2013) desdobra-se para além do movimento de mulheres e aciona modos e lugares outros de estar na comunidade. A inserção e participação política produzem modos de subjetivação ao longo da vida.

Claro, semana passada, retrasada, ainda fui na... na reunião da liderança da comunidade, do padre, eu fui lá, quando tem reunião dos idosos, da assembleia eu tô lá, quando tem reunião do sindicato, eu tô lá, quando tem reunião, quando participei, tava na diretoria, tô na diretoria do clube do lar eu vou... (TR2, 69 anos).

Ao ocuparem os espaços tradicionalmente delegados aos homens, as mulheres precisam refletir como compor modos de presidir, liderar, como falar para serem escutadas e, ao mesmo tempo, não repetirem comportamentos e modos de se posicionar atribuídos historicamente e criticados aos/nos homens. A desnaturalização da cultura machista, com seus "modo de ser masculino e feminino", exige reinvenção de si.

O presidente que era homem pode fazê os erros... nós temos, nós mulheres temos isso dentro de nós. Não queremos errar. Erramos, falhamos, mas a gente sempre procura e a gente se, se culpa muito [...] Então, fala, tu fala pros homens, então era muita rejeição. No comício debochavam da gente. Uma noite quando eu ia fala começa a fala dai tinha as gargalhada, abusadas [...] E meu deus, achava que ia nasce o meu filho naquela noite [...] no sétimo mês da gravidez [...] Sei que era um silêncio total naquela noite. Todo mundo, assim, fico. As mulheres só chorando, quem tava lá. E eu falando pra aqueles homes machão. Mas assim, foi acho que um... que me deu um pulso pra eu ainda mais começa a pensa na discriminação da mulher. (TR1, 56 anos)

Assim, a participação no movimento colocou em cheque as posições tradicionais de gênero atribuídas a homens e a mulheres. Ao pegar um microfone, mesmo em situações desfavoráveis e pouco amistosas, as mulheres ousaram trazer para o debate esses lugares historicamente cristalizados. A participação das mulheres, entretanto, segue sendo uma tarefa a ser conquistada diariamente, quando ainda é muito forte no imaginário feminino o seu não pertencimento aos espaços atribuídos à política

A própria questão na participação né na área da política elas muitas vezes não vão porque elas pensam, ah o que que ela sabe né, ah mulher só sabe de cozinha. (TR 5, 44 anos)

No entanto, mesmo com as dificuldades apontadas, as mulheres seguem resistindo e questionando os lugares a elas determinados

E eu não sei de onde que veio isso, nem porque e como... eu sei que eu enfrentei muito, meu pai... Até, sei lá né, não... eu fico meio indignada, eu sofri bastante sabe [...] né...que mulher é pra fica em casa [...] Eu não consigo, eu não nasci pra isso... sei... sei, sabe... não sirvo pra isso. (TR4, 46 anos).

E ainda,

devido a esse convívio com sindicato e várias experiências de pessoas né, de conhecer assim, parece que foi mais... não é que foi fácil também, tirar dos meus pais assim, que também tem saudade de casa, coisas que são normal. Mas acho que me preparou muito, preparação sabe? Pra enfrentar assim, buscar novos caminhos assim. (TR6, 32 anos)

Na procura de espaços outros, as instâncias de participação política contribuíram como espaço fértil para aberturas de possibilidades para (re)invenção de si.

\section{Discussão}

Ao analisar as falas de mulheres que ocupam posições de liderança no movimento de trabalhadoras rurais, e ao refletir como seus modos de vida são afetados pela participação política, pudemos acompanhar as complexas relações que se estabelecem entre os conceitos trabalhados. Se por um lado, mostra-se difícil a tarefa de descrevê-las em toda sua amplitude, a tentativa concentrou-se em mostrar suas interdependências.

Assim, a participação política operou como dispositivo de subjetivação ao produzir posições outras, 
de ser mulher. Conduziu a questionamentos sobre seus modos de vida, ao tomar que o privado também é político e pautar possibilidades de mudanças no cotidiano. Ainda que, em sua maioria, estas mulheres tenham chegado ao movimento social motivadas pelas críticas e/ou mal-estares em suas vidas cotidianas, essa mesma participação política gerou força e promoveu níveis outros de autonomia, assim como uma identidade política aos poucos consolidada.

Esta identidade política operou laços entre as questões individuais e coletivas nos diferentes espaços e cotidianidades, atrelando participação e subjetivação. A participação política implicou no fortalecimento e na convicção da necessidade da luta por seus direitos, e se constituiu em um motor propulsor das mudanças que foram acontecendo.

Com a inserção das mulheres em diferentes espaços de atuação novos posicionamentos subjetivos e sociais foram produzidos. A participação política do grupo de mulheres estudadas extrapola o movimento social e instaura-se em vários espaços da comunidade como: sindicatos, cooperativas, políticas públicas de saúde e dos direitos das mulheres, grupos comunitários e religiosos, partidos políticos, câmara de vereadores e organizações não-governamentais.

As pautas em prol dos direitos sociais e previdenciários foram consensuais, já as discussões sobre as questões de gênero e dos direitos da mulher, em suas especificidades foram sendo delegadas a segundo plano por apresentarem divergências. As discussões de gênero, em que pesem os avanços e conquistas ao longo dos anos, ainda permanecem como um desafio. Um dos focos está na integração e criação de novas políticas para as mulheres que promovam arranjos de gestão participativa, que possibilitem o fortalecimento de seu lugar no desenvolvimento territorial.

Cabe salientar, mesmo frente as dificuldades apontadas, que a participação política abriu espaços para reflexões consideradas do espaço privado como político. Com a inserção das mulheres em diferentes espaços de atuação, novos posicionamentos subjetivos foram produzidos. A inserção e discussão desses assuntos pelo movimento provocou instabilidade nas tradições consideradas dominantes no campo (Schaaf, 2003). Por sua vez, os avanços e as conquistas ao longo dos anos impressas pelo movimento são inegáveis (Brumer, 2002).

\section{Considerações Finais}

Ao traçar como objetivo deste estudo analisar as narrativas de mulheres que ocupam posições de liderança no movimento de trabalhadoras rurais, e refletir como os modos de vida são afetados pela participação política direcionamos nossas problematizações para os elementos subjetivos que contribuem para inserção e participação no movimento social.

O contexto da inserção e participação das mulheres é marcado pelo período de redemocratização do país e pela efervescência dos movimentos sociais. A constituição do movimento de mulheres trabalhadoras rurais aconteceu pela miscigenação de diferentes forças, atrelada, de um lado, às ideias associadas à Teologia da Libertação, e de outro, ao movimento sindical de base marxista e, ainda, com influências do movimento feminista com discussões sobre os modos de vida impostos às mulheres. Essa composição, em sua heterogeneidade, contribuiu para a abertura e o diálogo com diferentes grupos e organizações que impulsionaram as bandeiras de lutas defendidas pelo movimento de mulheres. Por sua vez, os diferentes modos de compreender e se posicionar defendidos por diferentes ideologias associadas a essas instituições, não raro, também ocasionaram tensionamento e divergências em relação às prioridades a serem assumidas pelo movimento de mulheres e sua agenda

No contexto rural, permeado por uma cultura patriarcal de dominação masculina, o homem aparece como companheiro ao estar presente e compartilhar das reivindicações das bandeiras de lutas, mas, também, como opressor, ao ocupar um lugar delegado pela sociedade capitalista que hierarquiza as posições de "ser homem e de ser mulher" permeadas por relações de dominação. Nesse sentido, é significativa a importância política que as mulheres trabalhadoras rurais tiveram ao longo da história e, ainda têm nas lutas sociais. Lutas essas em prol da melhoria das condições de vida das mulheres e homens trabalhadores do campo.

A participação política, ao demarcar posicionamentos coletivos do movimento social aciona modos de vida produzidos por diferentes posicionamentos subjetivos, trazendo para o centro discussões atreladas ao privado como político. Ela agencia e condiciona modos de subjetivação para além daqueles naturalizados historicamente no cotidiano patriarcal do campo. Os jogos de forças acionados em meio à inserção das mulheres nas questões políticas operam como dispositivo de subjetivação.

Os lugares demarcados tradicionalmente foram questionados e novos espaços de participação foram conquistados pelas mulheres no espaço público. A partir das narrativas das líderes do movimento, em que pese os avanços conquistados, o reconhecimento 
e a ampliação da atuação das mulheres em espaços de representatividade segue sendo um desafio. Tendo em vista, a escassez da literatura associada as discussões sobre participação política e subjetividade recomenda-se a ampliação dos estudos com enfoque nessa temática.

\section{Referências}

Braun, V. \& Clarke, V. (2006). Using thematic analysis in psychology. Qualitative Research in Psychology, 3, 77-101.

Brumer, A. (2002). Previdência social rural e gênero. Sociologias, 4(7), 50-81. http://dx.doi.org/10.1590/S151745222002000100003

Cardona, M. C. G. \& Cordeiro, R. M. (2010). A previdência rural e a constituição de modos de ser mulher trabalhadora rural no Sertão de Pernambuco. In S. J. Souza, M. Moraes. Tecnologia e modos de ser no contemporâneo, (pp. 157-184). Rio de Janeiro: PUC-Rio/7 Letras.

Clarke, V. \& Braun, V. (2013).Teaching thematic analysis: over-coming challenges and devoloping strategies for effective learning. The psychologist, 26(2), 120-123.

Costa, F. A., Machado, F. V., \& Prado, M. A. M. (2008). Participação política e experiência homossexual: dilemas entre o indivíduo e o coletivo. Interamerican Journal of Psychology, 42(2), 325-337.

Daron, V. L. P. (2003). Educação, cultura popular e saúde: experiências de mulheres trabalhadoras rurais. Dissertação apresentada no curso de pós-graduação em Educação, da Faculdade de Educação da Universidade de Passo Fundo, RS.

Fernández, A. M. (2008). Politica y Subjetividad - asambleas barriales y fábricas recuperadas. Buenos Aires: Biblos.

Foucault, M. (1979/1995). Microfisica do Poder. Rio de Janeiro: Graal.

Guareschi, N., Oliveira, F., Giannechini, L., Comunello, L., Pacheco, M., \& Nardini, M. (2002). As relações raciais na construção das identidades. Psicologia em Estudo (Maringá), 7(2), 55-64. http://dx.doi.org/10.1590/S141373722002000200007

Maciazeki-Gomes, R. C., Nogueira, C., \& Toneli, M. J. F. (2016). Mulheres em contextos rurais: um mapeamento das produções acadêmicas sobre gênero e ruralidade entre 2000-2014. Psicologia \& Sociedade, 28(1), 115-124. http:// dx.doi.org/10.1590/1807-03102015v28n1p115

Nogueira, C. (2011). Introdução à Teoria da Interseccionalidade nos Estudos de Género. In S. Neves (org.). Género e Ciências Sociais (pp. 67-78). Castelo da Maia: Edições ISMAI.

Nogueira, C. (2013). A teoria da interseccionalidade nos estudos de gênero sexualidades: condições de produção de "novas possibilidades" no projeto de uma psicologia feminista crítica. In A. V. Zanella, A. L, Brizola, \& M. Gesser (org.). Práticas sociais, políticas públicas e direitos humanos (pp. 227-248). Florianópolis: ABRAPSO/Edições do Bosque CFH/UFSC.

Oliveira, J. M. (2012). O rizoma "género": cartografia de três genealogias. E-cadernos CES [Online]. http://dx.doi. org $/ 10.4000 /$ eces. 962

Paulilo, M. I. \& Silva, C. B. (2007). A luta das mulheres agricultoras: entrevista com Dona Adélia Schmitz. Revista Estudos Feministas, 15(2), 399-417. http://dx.doi.org/10.1590/S0104-026X2007000200007

Pinto, N. M. A., Pontes, F. A. R., \& Silva, S. S. C. (2013). A Rede de Apoio Social e o Papel da Mulher na Geração de Ocupação e Renda no Meio Rural. Temas em Psicologia, 21(2), 297-315. http://dx.doi.org/10.9788/TP2013.2-01

Prado Filho, K. (2014). Para uma genealogia da Psicologia. In N. Guareschi, S. M. Hüning, M Azambuja. (Org.). Foucault e Psicologia na produção do conhecimento (pp. 107-124). Porto Alegre: EdiPUCRS.

Prado, M. A., Campici, C., \& Pimenta, S. (2004). Identidade coletiva e política na trajetória de organização das trabalhadoras rurais de Minas Gerais: para uma psicologia política das ações coletivas. Psicologia em Revista, 10(16), 298-317.

Prado, M. A. \& Toneli, M. J. (2013). Política e sujeitos coletivos: entre consensos e desacordos. Estudos de Psicologia, 18(2), 351-357. http://dx.doi.org/10.1590/S1413-294X2013000200022

Sales, C. M. V. (2007). Mulheres rurais: tecendo novas relações e reconhecendo direitos. Revista Estudos Feministas, 15(2), 437-443. http://dx.doi.org/10.1590/S0104-026X2007000200010

Salvaro, G. I. J., Lago, M. C. S., \& Wolff, C. S. (2013). Mulheres agricultoras e mulheres camponesas: lutas de gênero, identidades políticas e subjetividades. Psicologia \& Sociedade, 25(1), 79-89. http://dx.doi.org/10.1590/S010271822013000100010

Salvaro, G. I. J., Lago, M. C. S., \& Wolff, C. S. (2014). Limites e possibilidades da militância política em um movimento social rural de mulheres. Revista Estudos Feministas, 22(1), 51-70. http://dx.doi.org/10.1590/S0104026X2014000100004

Scott, J. W. (1998). A invisibilidade da experiência. Projeto História, 16, 297-325. 
Rodrigues, H. C. (2014). Para desencaminhar o presente Psi: biografia, temporalidade e experiência em Foucault. In N. Guareschi, \& S. M. Hüning (org). Foucault e Psicologia (pp. 7-27). Porto Alegre: EdiPUCRS.

Schaaf, A.V. D. (2003). Jeito de mulher rural: a busca de direitos sociais e da igualdade de gênero no Rio Grande do Sul. Sociologias, 10, 412-442. http://dx.doi.org/10.1590/S1517-45222003000200014

Tedeschi, L. A. (2007). Do silêncio a palavra: identidades e representações sociais de mulheres camponesas no Noroeste do RS. In Anais do XXIV Simpósio Nacional de História (pp. 1-9). São Leopoldo: UNISINOS.

Nota:

Agência de fomento $\mathrm{CNPq}$ - Bolsa de Demanda Social concedida à primeira autora, doutoranda em Psicologia na Faculdade de Psicologia e Ciências da Educação da Universidade do Porto.

Dados das autoras:

Rita de Cássia Maciazeki-Gomes - Doutoranda, Universidade do Porto, Portugal.

Conceição Nogueira - Doutora, Universidade do Porto, Portugal.

Claudia Lazcano Vázquez - Doutoranda, Universidade Federal de Santa Catarina, Brasil

Maria Juracy Toneli - Pós-Doutoranda, Universidade Federal de Santa Catarina.

Endereço para correspondência:

Rita de Cássia Maciazeki Gomes

Faculdade de Psicologia e Ciências da Educação da Universidade do Porto

Rua Alfredo Allen, 4200-135

Porto, Portugal

<ritamaciazeki@gmail.com>

Recebido em: 29.09.2015

Aceito em: 20.04.2016 